\title{
Megaendoprostheses in the management of malignant tumors of the lower extremities-risk factors for revision surgery
}

Moritz von Salis-Soglio ${ }^{\dagger}$, Mohamed Ghanem $^{\dagger}$, Christian Lycke, Andreas Roth and Georg Osterhoff (B)

\begin{abstract}
Background: Improved oncological and surgical measures now enable curative treatment of malignant lower extremity tumors in majority of cases. Complication rates associated with surgical resection of lower extremity tumors and replacement with megaendoprostheses are high. The aim of this study was to identify risk factors that predispose to revision surgery following the use of megaimplants in curative treatment of malignant tumors of the lower extremities.
\end{abstract}

Methods: this retrospective study included patients aged $\geq 18$ years who underwent implantation of a megaendoprosthesis for tumors or metastatic lesions of the lower extremities between January 2010 and December 2020. Baseline characteristics and information on adjuvant treatment, hospitalization time, comorbidities, mobility, complications, and revision surgery were considered. Primary outcomes were revision surgery and reasons for revision. Secondary outcomes were in-hospital complications and the duration of hospitalization.

Results: Fifty-four patients (48\% female, age 63 years, SD 15) were available for final analysis. Surgeries were performed at hip level in 37 patients (68.5\%) and at knee level in 17 patients (31.5\%). Revision for wound-related causes was performed in 12 cases (22.2\%), with microbiological proof of infection in 8 cases (14.8\%). Revision for hip joint instability was carried out in 4 cases (7.4\%) and for disconnection between components of the megaimplant in 2 cases (3.7\%). Those patients requiring a wound-related revision had undergone a longer primary surgical intervention than those who required an implant-related revision (276 vs $134 \mathrm{~min}, p=.002$ ). Wound drains after the primary implantation remained longer in situ in patients who later required revision surgery for woundrelated complications (5 vs 3 days, $p=.020$ ). An ASA $>3$ was associated with an increased likelihood for in-hospital complications in general $(p=.041)$, and in-hospital death in particular $(p=.012)$.

Conclusions: The management of malignant tumors of the lower extremities with megaendoprostheses is associated with a high rate of wound-related complications. Swift surgical performance and early postoperative removal of wound drains minimize the risk of complications in general and the necessity of revision surgery in particular. Patients with more comorbidities were more likely to suffer in-hospital complications.

Keywords: Tumor, Cancer, Megaimplants, Total hip replacement, Total knee replacement, Endoprosthesis, Complications, Risk factors

\footnotetext{
* Correspondence: georg.osterhoff@medizin.uni-leipzig.de

${ }^{\dagger}$ Moritz von Salis-Soglio and Mohamed Ghanem contributed equally to this work and share the first authorship.

Department of Orthopaedics, Trauma and Plastic Surgery, University Hospital Leipzig, Liebigstr. 20, 04103 Leipzig, Germany
}

C C The Author(s). 2021 Open Access This article is licensed under a Creative Commons Attribution 4.0 International License, which permits use, sharing, adaptation, distribution and reproduction in any medium or format, as long as you give appropriate credit to the original author(s) and the source, provide a link to the Creative Commons licence, and indicate if changes were made. The images or other third party material in this article are included in the article's Creative Commons. licence, unless indicated otherwise in a credit line to the material. If material is not included in the article's Creative Commons licence and your intended use is not permitted by statutory regulation or exceeds the permitted use, you will need to obtain permission directly from the copyright holder. To view a copy of this licence, visit http://creativecommons.org/licenses/by/4.0/ The Creative Commons Public Domain Dedication waiver (http://creativecommons.org/publicdomain/zero/1.0/) applies to the data made available in this article, unless otherwise stated in a credit line to the data. 


\section{Introduction}

The demographic shift toward an elderly population is inevitably linked to an increase in the incidence of malignant primary tumors and metastases in the musculoskeletal system [8, 14]. A few decades ago, the treatment of malignant bone tumors involved amputation of the affected limb. The introduction of megaimplants as an alternative to amputation therefore represented a milestone of particular relevance to the treatment of malignant bone tumors of the lower extremities [14, 26].

Metastases manifest with different rates of incidence in the long bones, most commonly in femur, humerus, and tibia [5], particularly in metadiaphyseal sections.

The improved (neo-) adjuvant chemotherapy, radiotherapy and surgical measures using modular megaimplants have made an in sano resection of tumors with concommitant extremity preservation possible in the vast majority (approx. 90\%) of cases [1, 6, 14, 24, 26].

The overall survival rate after resection of primary malignant bone tumors has been improved in recent years and now ranges from 61 to $92 \%$. Similarly, the survival time of those patients who develop skeletal metastases has also improved with 5-year survival rates currently approaching 30\%) [1, 24].

Implantation of mega-endoprostheses in patients after tumor resection mainly serves to reduce pain, reconstruct the length of the extremity and restore mobility $[11,20]$.

Surgical management of malignant tumors of the lower extremities with skeletal reconstruction using mega-implants is a complex intervention that can expose multimorbid patients in particular to perioperative risks and complications $[6,8,15,26]$.

The relatively limited number of tumor endoprosthetic procedures, the variety of individual indications and the different modalities of additional oncological therapy such as (neo-)adjuvant chemotherapy and radiotherapy has led unavoidably to a significant degree of heterogeneity in cases included in scientific studies. This imposes an important limitation the number of studies and classifications available [13] and has resulted in the vast majority of studies of megaendoprostheses being focused on analyses of post-surgical complications such as infection, dislocation, aseptic loosening and disconnection of modular parts $[6,8,10,14,26]$.

This study was designed to identify risk factors predisposing to revision surgery and to assess the overall rate of revision surgery after implantation of megaimplants in the context of curative surgery of malignant tumors of the lower extremities. Our aim is the informed adjustment of treatment strategies to minimize the need for revision surgery in the interests of both patient welfare and cost-effectiveness. These aspects are in line with context of translational orthopedics filing the gap between research and clinical practice [21].

\section{Material and methods}

A monocentric retrospective cohort study was conducted at an academic orthopedic center. The protocol of this study was approved by the institutional ethics committee.

\section{Patients}

Consecutive patients aged $\geq 18$ years who underwent implantation of a megaendoprosthesis for tumors or metastatic lesions of a lower extremity between January 2010 and December 2020 with a minimum follow-up of 3 months were identified from the authors' hospital information system. A retrospective chart review was performed for all patients identified as eligible. Patients with diaphyseal or total femur replacement were excluded, as were those who had expressed objection to the use of their data for research purposes.

Baseline characteristics and information on adjuvant treatment, hospitalization time, comorbidities, mobility, complications, and revision surgery were obtained. The ASA physical status classification system (ASA) of the American Society of Anesthesiologists was documented for all patients.

\section{Outcome}

Primary outcomes were revision surgery and reasons for revision. Secondary outcomes were in-hospital complications and duration of the hospitalization.

\section{Statistical analysis}

Statistical analysis was performed in SPSS 25.0 (SPSS Inc., Chicago, IL, USA). Unless otherwise denoted, data were summarized as mean and standard deviation (SD).

Nominal variables were associated using chi-square or Fisher's exact tests and non-parametric tests were used to compare continuous data. To determine the prognostic value of potential factors identified in the exploratory analysis, a binary logistic regression analysis was performed and odds ratios with a confidence interval (CI) of $95 \%$ were calculated. The level of statistical significance was set at $p<0.05$.

\section{Results}

Fifty-four patients with tumor-endoprostheses (26 females, 48\%) were available for final analysis. The mean age was 63 years (SD 15, range, 19 to 81) and mean follow-up was 18 months (SD 25, range, 3 to 113). Thirty-one patients $(57.4 \%)$ had a malignant primary bone tumor, while a metastatic bone lesion was resected in 23 cases (42.6\%). Metastatic disease was present in 34 patients $(63.0 \%)$.

Most patients had pre-existing comorbidities with cardiovascular diseases being the most frequent (74.0\%), followed by diseases of the lung (20.4\%), and diabetes 
mellitus (18.5\%). The median ASA was 3 (range, 1 to 4 ) with 28 patients scaled ASA 3 (51.9\%), 22 scaled ASA 2 (40.7\%), 3 scaled ASA 4 (5.6\%), and 1 patient with an ASA of 1 (1.9\%).

Surgeries were performed at hip level in 37 patients $(68.5 \%)$ and at knee level in 17 patients (31.5\%, Figs. 1 and 2). The mean duration of the tumor resection and primary implantation of a megaendoprosthesis was 229 min (SD 111) and the mean length of hospitalization was 19days (SD 13, range, 6 to 72). Wound drains were applied intraoperatively in 50 patients (92.6\%) and removed after mean 4 days (SD 2, range, 1 to 7 ).

\section{Revision surgery}

Revision surgery was necessary in 18 patients (33.3\%) after median 29 days (range, 9 to 3195 days, Table 1, Fig. 3).

Revision for wound-related causes was performed in 12 cases $(22.2 \%)$, with microbiological proof of infection in 8 cases $(14.8 \%)$. Revision for implant-related causes was carried out in 6 cases $(11.1 \%)$, with hip joint instability in 4 cases $(7.4 \%)$ and disconnection within the megaimplant in 2 cases (3.7\%). No revisions for implant loosening were necessary during the observed follow-up interval. In 2 patients (3.7\%) histological examination revealed an insufficient safety margin after tumor resection. Therefore, revision surgery was performed with subsequent histological proof of in sano resection.

Patients requiring a wound-related revision had undergone a primary surgical intervention that was significantly longer than that for patients requiring an implant-related revision (276 vs $134 \mathrm{~min}, p=.002$ ).

Wound drains after the primary implantation remained in situ longer in those patients who later required revision surgery for wound-related complications (5 days, SD 2) than they did either in patients who required implant-related revisions (3 days, SD 1, $p=.020$ ) or in all patients without a wound-related complication (4 days, SD 1, $p=0.014$ ). Logistic regression analysis revealed that each additional day of leaving the drains in situ increases the likelihood of a revision for woundrelated complications by $112 \%$ (coefficient $B=0.752$, OR 2.121, 95\% CI 1.128, 3.987)

\section{In-hospital complications}

In-hospital complications not directly related to the surgical wound or the implant itself were seen in 7 patients (13.0\%). This included 2 cases with cardiovascular events (3.7\%), 2 pulmonary embolisms (3.7 \%), 2 cases with pneumonia $(3.7 \%)$, and 1 urinary tract infection $(1.9 \%)$. These complications were lethal in 4 (7.4\%) patients. No other in-hospital complications were observed.

Patients who died during the hospitalization were significantly older (mean 76 years, SD 6 vs. 61 years, SD 15, $p=.039$ ). Patients with pre-existing pulmonary diseases were more likely to have an in-hospital pneumonia ( $p=$ .038), and patients under ongoing chemotherapy during the surgery were more likely to have a cardiovascular event $(p=.031)$. An ASA > 3 was associated with an increased likelihood for in-hospital complications in general $(p=.041)$, and in-hospital death in particular $(p=$ .012). Logistic regression analysis revealed that patients with an ASA > 3 had an odds ratio of 0.020 (95\% CI $0.001,0.331$, coefficient $B=-3.892$ ) for death during hospitalization.

\section{Hospitalization time}

The duration of the initial surgery showed a strong correlation with the duration of the entire hospital stay (Pearson's $r=.614, p<.001$ ), while there was only a very weak association between the time to wound drain removal and hospital stay (Pearson's $r=.321, p=.043$ ).

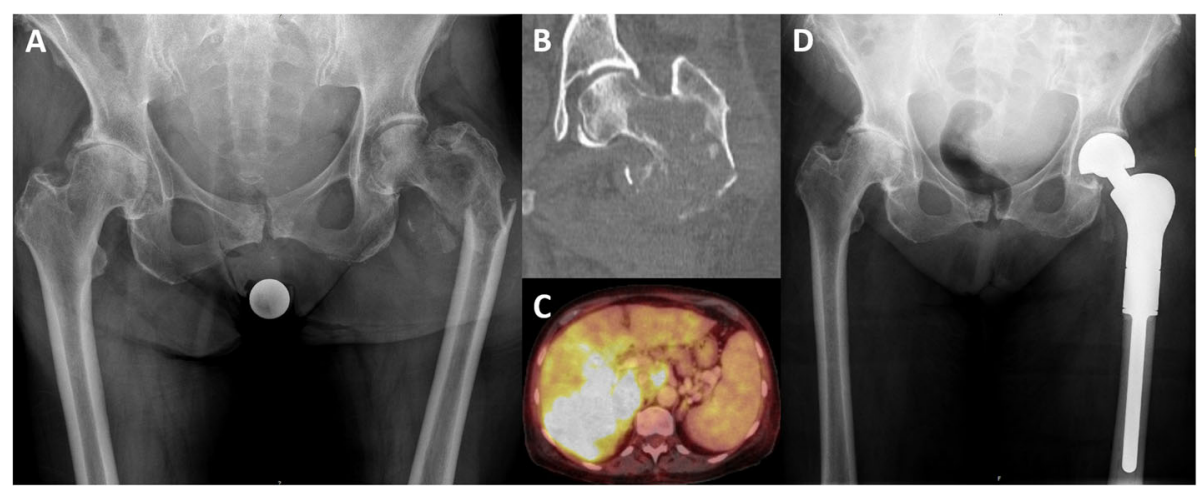

Fig. 1 Case of a 70-year-old female patient with a pathological proximal femur fracture due to a metastatic lesion of a cholangiocellular carcinoma (CCC, UICC Stadium IV). A Conventional radiography showing pathological fracture of the left femur. B Computed tomography (CT) shows a lytic lesion of the proximal femur. C PET-CT scan with a large malignant tumor of the liver that histologically revealed to be a CCC. D Postoperative antero-posterior radiograph after resection and replacement of the proximal femur 


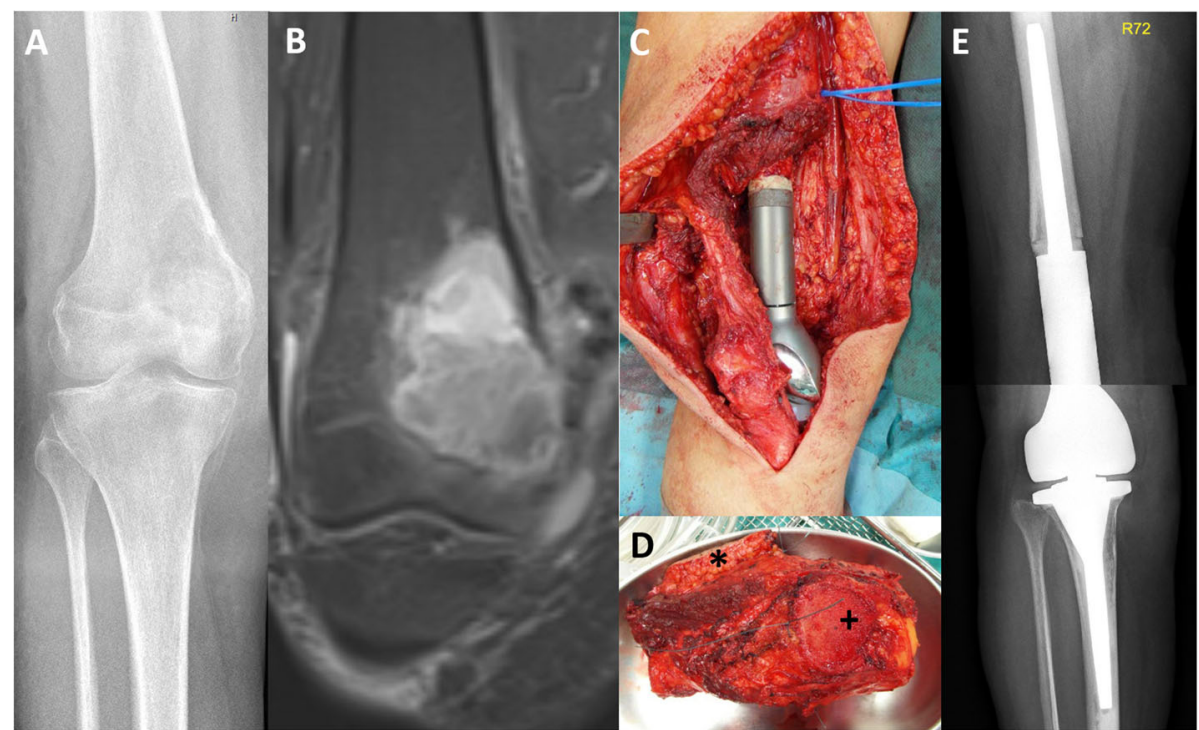

Fig. 2 Case of a 75-year-old female patient with a Ewing-like sarcoma of the right distal femur with infiltration of the joint space. A Conventional radiography showing the osteolytic lesion. B Magnetic resonance imaging with contrast agent shows erosion of the articular cortex of the medial femur condyle. C Intraoperative photograph after extra-articular knee resection and implantation of a megaimplant. The patella was split in the coronal plane. D Resected knee (top: medial, left: proximal) with the articular part of the patella $\left(^{*}\right)$ and the biopsy scar (+) attached to it. E Postoperative antero-posterior radiograph

Table 1 Reasons for and type of revision surgeries

\begin{tabular}{|c|c|c|c|c|c|}
\hline & Age & Sex & Type of implant & Reason for revision & Type of revision \\
\hline \multirow[t]{6}{*}{$\begin{array}{l}\text { Implant- } \\
\text { related }\end{array}$} & 71 & Male & Distal femur & $\begin{array}{l}\text { Functional due to mechanical problem with } \\
\text { connector }\end{array}$ & Change of connector and inlay \\
\hline & 77 & Female & Prox. femur & Hip dislocation & Open reduction, change of head \\
\hline & 53 & Female & Prox. femur w/ THA & Hip dislocation & Closed reduction \\
\hline & 44 & Female & Prox. femur w/ THA & Hip dislocation & $\begin{array}{l}\text { Change of acetabular component, } \\
\text { constrained inlay }\end{array}$ \\
\hline & 72 & Male & Prox. femur & Hip dislocation & Open reduction, change of head \\
\hline & 51 & Female & Dist. femur & Arthrofibrosis & Arthrolysis, change of connector and inlay \\
\hline \multirow[t]{12}{*}{$\begin{array}{l}\text { Wound- } \\
\text { related }\end{array}$} & 71 & Male & Prox. femur & SSI & $\begin{array}{l}\text { Lavage, change of modules, stem left in } \\
\text { place }\end{array}$ \\
\hline & 72 & Male & Prox. femur & SSI & Lavage, change of inlay \\
\hline & 77 & Female & Dist. femur & SSI & Lavage, change of inlay \\
\hline & 78 & Male & Prox. femur & SSI & Lavage, change of inlay \\
\hline & 70 & Female & Dist. femur & SSI & Lavage, implant removal, spacer \\
\hline & 78 & Male & Prox. femur & SSI & Lavage, implant removal, spacer \\
\hline & 77 & Male & Dist. femur & SSI & Lavage, change of inlay \\
\hline & 71 & Female & Prox. femur & SSI & Lavage, change of inlay \\
\hline & 53 & Female & Prox. femur & Wound seroma & Lavage \\
\hline & 44 & Male & Dist. femur & Wound seroma & Lavage, change of inlay \\
\hline & 67 & Male & Prox. femur & Hematoma & Lavage \\
\hline & 37 & Male & $\begin{array}{l}\text { Acetabular } \\
\text { replacement }\end{array}$ & Wound dehiscence & Free flap coverage \\
\hline \multirow[t]{2}{*}{$\begin{array}{l}\text { Tumor- } \\
\text { related }\end{array}$} & 71 & male & $\begin{array}{l}\text { Acetabular } \\
\text { replacement }\end{array}$ & Local recurrence & Hip exarticulation \\
\hline & 75 & female & Dist. femur & $\mathrm{R} 1$ resection & Re-resection \\
\hline
\end{tabular}




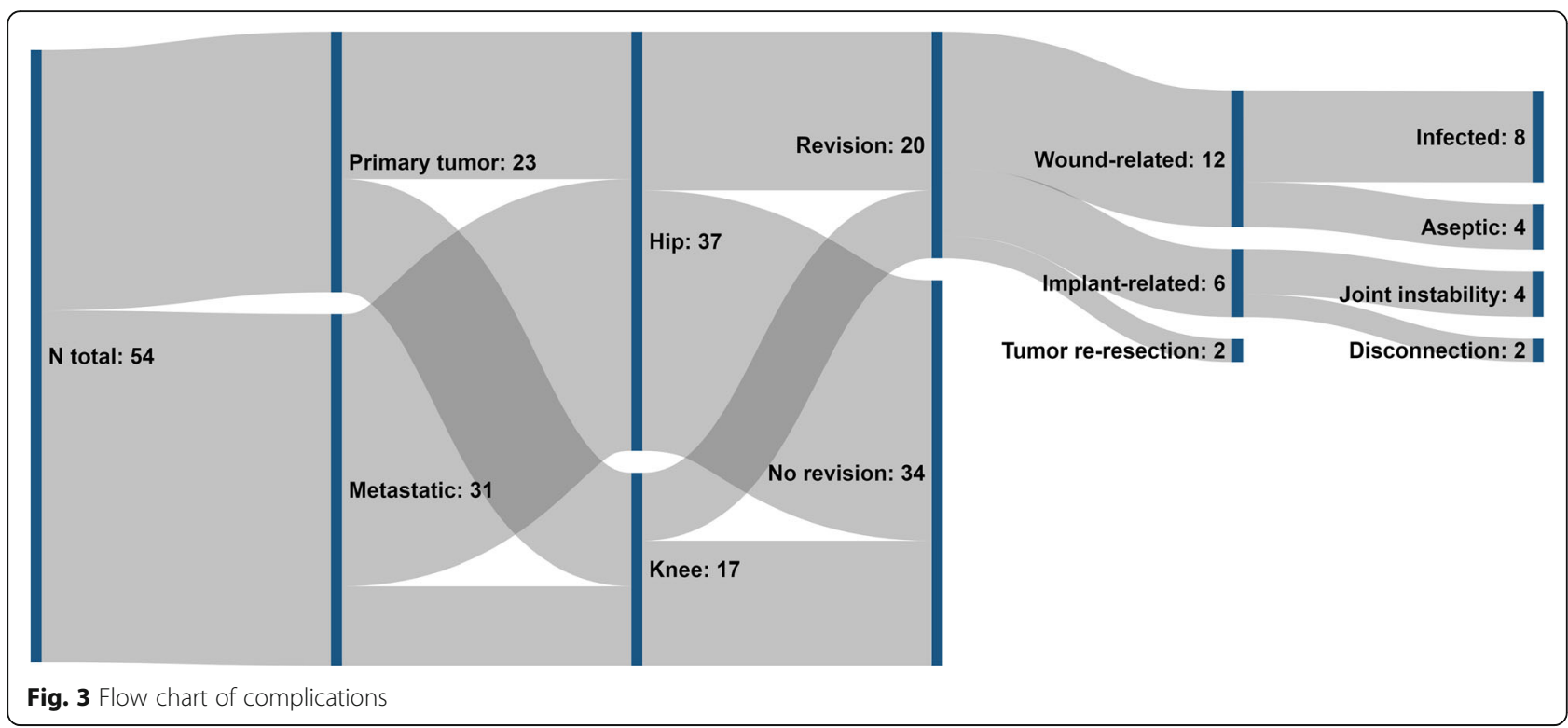

\section{Discussion}

In this study, the observed overall rate of revision surgery after implantation of megaimplants in the management of tumors of the lower extremity was $33.3 \%$ after median 29 days (range, 9 to 3195 days).

Most studies published to date have focused on the rate of a particular complication such as dislocation, infection, loosening or disconnection of modular parts [2, $4,6,8,9,12,17,18,22,26-28]$. To the best of our knowledge, only few studies have evaluated the overall rate of revision surgery after resection of malignant tumors of the lower extremity with subsequent reconstruction with megaendoprostheses [25].

Implant-specific complications, such as disconnection or material breakage occurred rarely in the patient population analyzed here (3.7\%), in line with similar studies reported in literature [26]. Despite being an initial concern, the disconnection of modular parts no longer plays an essential role in large megaendoprosthesis systems $[25,26]$.

In 4 of our cases (7.4\%), we performed revision surgery due to joint instability of the hip after proximal femoral replacement. Rates of dislocation between $2 \%$ and $28 \%$ have been reported in the literature, with the wide range reflecting heterogeneity both within and between the patient populations [3, 11, 17-19, 23, 29]. The dislocation rate of $7.4 \%$ in our cohort which is based on partial pelvic replacement, proximal femoral replacement, and total femoral replacement is comparable to that observed in other studies. Nonetheless, the course of treatment necessitated by dislocation can involve reoperations or orthotic fittings and is often a significant burden.

The greatest challenge in the case of megaendoprostheses, however, is undoubtedly periprosthetic infection, which usually entails an extremely time-consuming and costly treatment. In our study, revision for woundrelated causes was performed in 12 cases $(22.2 \%)$, with microbiological proof of infection in 8 cases (14.8\%). Again, this is consistent with the infection rates between $3 \%$ and $36 \%$ that have been reported in the literature [2, $4,6,8,9,12,17,18,22,28]$. Importantly, our analysis clearly identified a longer duration of surgery and the delayed removal of wound drains following primary surgery as risk factors for wound-related revision surgery after implantation of megaendoprostheses.

As may be expected, patients who had pre-existing comorbidities were more likely to suffer from in-hospital complications not directly related to the wound or the implant itself.

The limitations of this study lie in its retrospective nature, the inhomogeneity of the patient population, and the fact that we were not able to evaluate any pre- and postoperative scores for the patients. However, these same limitations apply to the vast majority of studies that dealt with megaimplants in general, and megaimplants in management of tumors of the lower extremity in particular.

Although the minimum follow-up period of 3 months must be considered as a further limitation of our study, the average follow-up period was 18 months. In view of this, the fact that no revision surgery was carried out due to loosening of implants is undoubtedly a positive aspect.

Analysis of the survival rate of megaendoprostheses is complicated by the heterogeneity of the patient population and the underlying clinical characteristics. However, an increasing rate of loosening is observed from proximal femur replacement to distal femur replacement to 
proximal tibia or total femur replacement that is consistent with degrees of biomechanical load $[7,16]$.

\section{Conclusion}

Megaendoprostheses will undoubtedly continue to be of major relevance in tumor surgery of the lower extremity. They present technically feasible solutions in the most difficult situations involving large bone defects and usually facilitate the early mobilization and weight-bearing that is particularly important for the management of multimorbid patients.

Swift surgical performance and early postoperative removal of wound drains minimize the risk of complications in general and the necessity of revision surgery in particular.

Further studies with long-term follow-up are needed to identify further risk factors for complications and for revision surgery following tumor surgery of the lower extremity and reconstruction with megaimplants.

\section{Abbreviations}

ASA: American Society of Anesthesiologists Scale; CCC: Cholangiocellular carcinoma; SD: Standard deviation; UICC: Union for International Cancer Control

\section{Acknowledgements}

Not applicable.

\section{Authors' contributions}

MG and MvS participated in designing the study, the acquisition of data, and drafting of the manuscript. CL participated in the acquisition of data. AR participated in designing the study and revised the manuscript. GO participated in designing the study, drafted the manuscript, and did the statistical analysis. All authors read and approved the final manuscript.

\section{Funding}

There is no external funding source. Open Access funding enabled and organized by Projekt DEAL.

\section{Availability of data and materials}

Anonymized grouped data are available upon request from the corresponding author.

\section{Declarations}

\section{Ethics approval and consent to participate}

The study protocol of this study was approved by the institutional ethics committee (Ethik-Kommission der Medizinischen Fakultät der Universität Leipzig, reference: 020/21-ek). The study was conducted in accordance with all local regulations and followed the principles of the Helsinki Declaration. Informed consent was not obtained due to the retrospective nature of the study in accordance with $\S 34$ of the Saxon Hospital Act. Patients who earlier had expressed objection to the use of their data for research purposes were excluded.

\section{Consent for publication}

N/A

\section{Competing interests}

GO is Associated Editor of BMC Musculoskeletal Disorders. The other authors declare that they have no competing interests.
Received: 4 June 2021 Accepted: 30 July 2021

Published online: 18 August 2021

\section{References}

1. American Cancer Society. Cancer stat facts. 2017. https://seer.cancer.gov/sta tfacts/html/all.html

2. Ascherl R. Infektionsmanagement bei Megaimplantaten. Orthopäde. 2010; 39:980-93.

3. Bickels J, Meller I, Henshaw RM, Malawer MM. Reconstruction of hip stability after proximal and total femur resections. Clin Orthop Relat Res. 2000;375: 218-30. https://doi.org/10.1097/00003086-200006000-00027.

4. Donati D, Zavatta M, Gozzi E, Giacomini S, Campanacci L, Mercuri M. Modular prosthetic replacement of the proximal femur after resection of a bone tumour a long-term follow-up. J Bone Joint Surg (Br). 2001;83(8):115660. https://doi.org/10.1302/0301-620X.83B8.0831156.

5. Freyschmidt J, Ostertag H, Jundt G. Knochentumoren: Klinik, Radiologie, Pathologie. Berlin, Heidelberg, NewYork: Springer; 1998.

6. Fritzsche $\mathrm{H}$, Hofbauer $\mathrm{C}$, Winkler $\mathrm{D}$, et al. Komplikationsmanagement nach Tumorendoprothesen. Orthopäde. 2019:48:588-97.

7. Gatha NM, Clarke HD, Fuchs R, Scuderi GR, Insall JN. Factors affecting postoperative range of motion after total knee arthroplasty. J Knee Surg. 2004;17(4):196-202. https://doi.org/10.1055/s-0030-1248221.

8. Ghanem M, Schneider I, Zajonz D, Pempe C, Goralski S, Fakler JKM, et al. Management of modular mega-implant infection of the lower extremity. Z Orthop Unfall. 2021. https://doi.org/10.1055/a-1340-0890.

9. Gosheger G, Winkelmann W. Mutars- ein modulares Tumor- und Revisionssystem. Erfahrungen am Tumorzentrum Münster. Orthopäde. 2000; 29(Suppl 1):S54-5.

10. Gosheger G, Gebert C, Ahrens H, Streitbuerger A, Winkelmann W, Hardes J. Endoprosthetic reconstruction in 250 patient with sarcoma. Clin Orthop Relat Res. 2006;450:164-71. https://doi.org/10.1097/01.blo.0000223978.3 6831.39.

11. Hardes J, Budny T, Hauschild G, Balke M, Streitbürger A, Dieckmann R, et al. Der proximale Femurersatz in der Revisions-alloarthroplastik. Z Orthop Unfall. 2009;147(06):694-9. https://doi.org/10.1055/s-0029-1185710.

12. Heisel C, Bernd L. Frühergebnisse nach Defektrekonstruktion an der unteren Extremität mittels MUTARS-Endoprothesen. Akt Traumatol. 2000:30:1-8.

13. Henderson ER, Groundland JS, Pala E, et al. Failure mode classification for tumor endoprostheses: retrospective review of five institutions and a literature review. J Bone Joint Surg Am. 2011;93:418-29.

14. Hillmann A, Ipach I. Tumorensoprothetik. Stellenwert in der modernen Revisionsendoprothetik. Orthopäde. 2015;44(5):375-80. https://doi.org/10.1 007/s00132-015-3086-z.

15. Höll S, Schlomberg A, Gosheger G, et al. Distal femur and proximal tibia replacement with megaprosthesis in revision knee arthroplasty: a limb saving procedure. Knee Surg Sports Traumatol Arthrosc. 2012;20:2513-8.

16. Horowitz SM, et al. Prostetic arthroplasty of the knee after resection of a sarcoma in the proximal end of the tibia. A report of sixteen cases. J Bone Joint Surg Am. 1991;73(A):286-93.

17. Ilyas I, Pant R, Kurar A, Moreau PG, Younge DA. Modular megaprosthesis for proximal femoral tumors. Int Orthop. 2002;26(3):170-3.

18. Jofe MH, Gebhardt MC, Tomford WW, Mankin HJ. Reconstruction for defects of the proximal part of the femur using allograft arthroplasty. J Bone Joint Surg Am. 1988;70(4):507-16. https://doi.org/10.2106/00004 623-198870040-00005.

19. Kabukcuoglu Y, Grimer RJ, Tillman RM, Carter SR. Endoprosthetic replacement for primary malignant tumors of the proximal femur. Clin Orthop Relat Res. 1999;358:8-14.

20. Malkani AL, Settecerri JJ, Sim FH. Long-term results of proximal femoral replacements for non-neoplastic disorders. J Bone Joint Surg (Br). 1995; 77(3):351-6.

21. Mediouni M, Schlatterer DR, Madry H, Cucchiarini M, Rai B. A review of translational medicine. The future paradigm: how can we connect the orthopedic dots better? Curr Med Res Opin. 2018;34(7):1217-29. https://doi. org/10.1080/03007995.2017.1385450 Epub 2017 Nov 1. PMID: 28952378.

22. Mittermayer F, Krepler $P$, Dokinkus M, Schwameis E, Sluga M, Heinzl H, et al. Long-term follow-up of uncemented tumor endoprostheses for the lower extremity. Clin Orthop Relat Res. 2001;388:167-77. https://doi.org/10.1097/ 00003086-200107000-00024.

23. Sim FH, Frassica FJ, Chao EY. Orthopaedic management using new devices and prostheses. Clin Orthop Relat Res. 1995;312:160-72. 
24. Streitburger A, Gosheger G, Dieckmann R, et al. Bone defect reconstruction in bone sarcoma surgery: tumour endoprosthesis versus biological reconstruction. Unfallchirurg. 2014;117:600-6.

25. Theil C, Röder J, Gosheger G, Deventer N, Dieckmann R, Schorn D, et al. What is the Likelihood That Tumor Endoprostheses Will Experience a Second Complication After First Revision in Patients With Primary Malignant Bone Tumors And What Are Potential Risk Factors? Clin Orthop Relat Res. 2019;477(12):2705-14. https://doi.org/10.1097/CORR.0000000000000955 PMID: 31764339; PMCID: PMC6907292.

26. von Salis-Soglio G, Ghanem M, Meinecke I, Ellenrieder M, Klinger HM, Kirchhoff C. Modulares Endoprothesensystem München-Lübeck (MML). Anwendungsmöglichkeiten und Ergebnisse an den unteren Extremitäten. Orthopade. 2010;39(10):960-7. https://doi.org/10.1007/s00132-009-1569-5.

27. Wirtz DC, Birnbaum K, Siebert CH, Heller KD. Bilateral total hip replacement in pseudoachondroplasia. Acta Orthop Belg. 2000:66(4):405-8.

28. Zajonz D, Zieme A, Prietzel T, Moche M, Tiepoldt S, Roth A, et al. Periprosthetic joint infections in modular endoprosthesis of the lower extremities.: a retrospective observational study in 101 patients. Patient Saf Surg. 2016;10(1):6. https://doi.org/10.1186/s13037-016-0095-8.

29. Zehr RJ, Enneking WF, Scarborough MT. Allograft-prosthesis composite versus megaprosthesis in proximal femoral reconstruction. Clin Orthop Relat Res. 1996:322:207-23.

\section{Publisher's Note}

Springer Nature remains neutral with regard to jurisdictional claims in published maps and institutional affiliations.

Ready to submit your research? Choose BMC and benefit from:

- fast, convenient online submission

- thorough peer review by experienced researchers in your field

- rapid publication on acceptance

- support for research data, including large and complex data types

- gold Open Access which fosters wider collaboration and increased citations

- maximum visibility for your research: over $100 \mathrm{M}$ website views per year

At BMC, research is always in progress.

Learn more biomedcentral.com/submissions 